\title{
MANUFACTURING OF HIGH-PERFORMANCE FORGING DIES BY AUSFORMING
}

\author{
'Bernd-Arno BEHRENS, ${ }^{1}$ Kai BRUNOTTE, ${ }^{1}$ Michael TILL \\ ${ }^{1}$ Institut für Umformtechnik und Umformmaschinen (Forming Technology and Machines), Leibniz Universität \\ Hannover, Garbsen, Germany, EU, \\ tillifum.uni-hannover.de, behrens@ifum.uni-hannover.de, brunotte@ifum.uni-hannover.de
}

https://doi.org/10.37904/metal.2020.3471

\begin{abstract}
During forging, dies are subject to a complex load collective caused by combined thermally and mechanically induced stresses. Crack formation and deformation on tool surfaces, as a result of low fatigue resistance, lead to tool failure and high process costs. Grain refinement is regarded as a method to improve fatigue resistance due to enhanced ductile material properties. To generate a fine-grained microstructure in the die material, increased deformation can be applied in the metastable austenite phase, also known as ausforming. In this study, the thermo-mechanical treatment ausforming will be used to form the final contour of forging dies. For this purpose, an analogy study was performed in which a preform is ausformed. It is investigated to what extent a fine-grained microstructure can be achieved in the final forming stage. The hot-working steel X37CrMoV5-1 (AISI H11) was used as specimen material. The developed sample geometry represents the inner contour of a highly mechanically loaded forging die. To achieve optimal properties, process routes with different cooling strategies and two defined true plastic strains were examined in metallographic analysis and hardness measurements according to EN ISO 6507-1 (HV1). It is shown that, after complete austenitisation, the highest hardness values can be achieved by applying a water-air spray cooling with subsequent forming. This could be demonstrated without material failure in the samples even with a high true plastic strain.
\end{abstract}

Keywords: Metastable austenite, ausforming, cooling rate, true plastic strain

\section{INTRODUCTION}

Tools used in forging operations are subject to a superimposed cyclic load spectrum, which differs depending on the geometry [1]. A typical failure mechanism in areas of small radii, which frequently occurs for highly mechanically loaded dies in addition to abrasion and deformation, is crack formation and propagation. The number of load bearing cycles is decisive for the efficiency of a forging process and defines the tool's service life $[2,3]$.

The aim of this study is to increase the service life of forging tools by improving the microstructural properties of hot working steels with regard to ductility while maintaining high hardness. The increase in hardness of conventional hot work steels, without loss of ductile properties, is limited in conventional thermal tempering processes. These properties (hardness and ductility) are crucial to counteract failure due to crack formation under high thermo-mechanical loads. The cyclical temperature change on the die surface leads to microplastic deformations and cracks in non-metallic inclusions and segregation carbides [4]. As depicted in Figure 1 (left), when producing such tools by machining, the grains are broken unfavorably, leading to low fatigue resistance in areas of small radii.

Ausforming is a method of improving the above-mentioned properties by adapting the microstructure alignment (texture) to the actual load [5] while simultaneously refining the grains [6] (Figure 1, right). During ausforming, deformation in the metastable austenite phase is transferred to the martensitic microstructure in a preceding quenching treatment. The lattice defects introduced by the deformation affect the solubility, the diffusion of 
foreign atoms, self-diffusion and thus the nucleation and growth of the phase during its allotropic transformation. By exploiting this effect, the strength properties of austenitic steels can be raised above those of conventionally tempered steels by means of exact temperature control and forming [7].

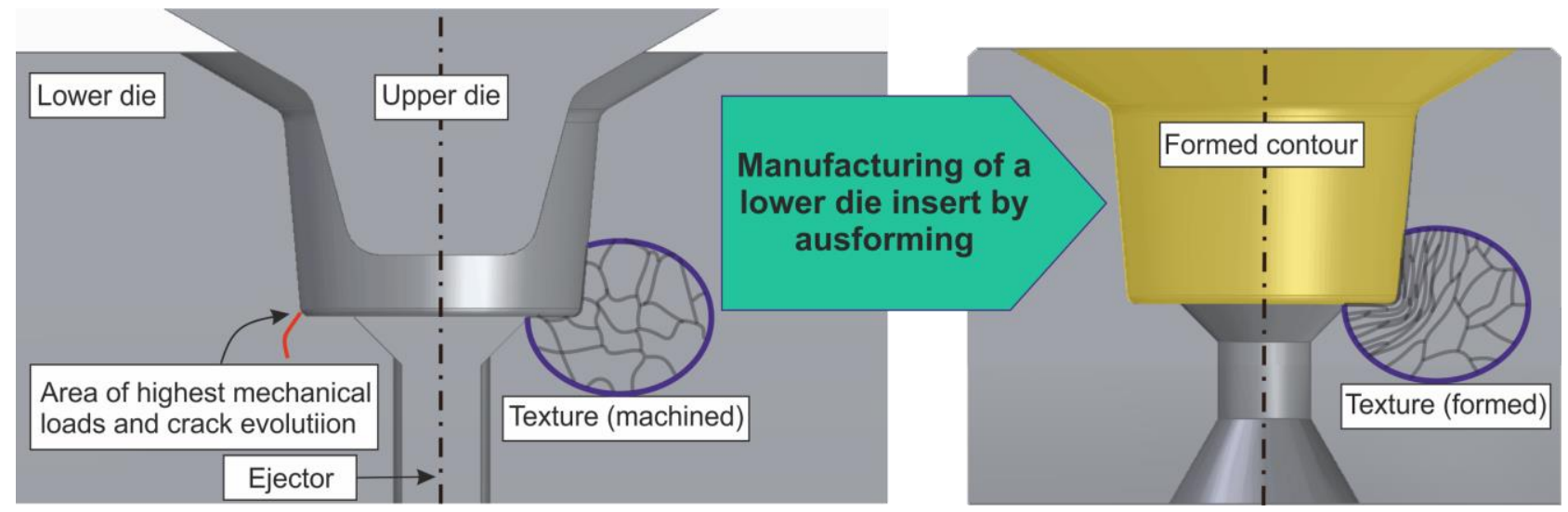

Figure 1 Typical failure in a machined lower die due to crack initiation (left) and die insert with the same contour produced by forming in the metastable austenite phase displaying the texture (right)

Ausforming of tool steels represents an alternative to quenching and tempering of machined tool contours and allows improved properties for forging dies. The combination of grain refinement and microstructural texturing should lead to an increase in service life.

The overall objective of this study is to produce a die as shown in Figure 1 (right) by ausforming. Its contour is subjected to a high mechanical load in the concave radius of the bottom area and thus represents a suitable demonstrator. For this purpose, fundamental investigations on ausforming of tool steel under variation of the true plastic strain and the cooling strategy were carried out to determine the required thermomechanical process parameters. Analogy experiments with cylinder upsetting tests were conducted representing the loaded bottom section of the above-mentioned tool contour, which is the focus of this contribution.

\section{METHOD}

By means of upsetting tests, material and process efforts can be significantly reduced while allowing the observation of several process influences. In order to be able to produce a die according to Figure 1 (right) analogy upsetting experiments were carried out, varying the cooling strategy and the true plastic strain. The process sequence of the analogy experiments is shown in Figure 2 using the example of a simplified continuous time-temperature-transformation (TTT) diagram.

The cylindrical workpieces $(\varnothing 25 \mathrm{~mm} \times 9 \mathrm{~mm} / 11 \mathrm{~mm}$ ) were made of hot working tool steel X37CrMoV5-1 (AISI H11). This steel grade contains austenite stabilizing elements such as $\mathrm{Cr}, \mathrm{Mo}, \mathrm{V}$ and is particularly suitable for the ausforming process due to its slower transformation kinetics in the austenite phase [8]. For the tests, the samples were austenised for $10 \mathrm{~min}$ in a batch furnace at $1060^{\circ} \mathrm{C}$, then cooled to the temperature range of metastable austenite and finally upset with a true plastic strain of $\varphi=0.25$ (9 mm initial height) or $\varphi=0.45$ (11 mm initial height).

In order to achieve the desired properties or rather to preserve the defects in the austenite and ensure increased dislocation density, forming must be carried out below recrystallization temperature and above martensite starting temperature. The martensite starting temperature decreases with decreasing grain size, since the nucleation of austenite in these structures is enhanced in comparison to coarser structures [6].The grain size depends on the selected heating and holding times [9]. The early formation of martensite at a high martensite starting temperature $M s_{1 b}$ can lead to cracks during ausforming. At higher forming temperatures an 
increased pearlite formation is assumed, which also limits the maximum forming temperature. Thus, the process window for the forming temperature measured on the surface was set to $500-600{ }^{\circ} \mathrm{C}$.

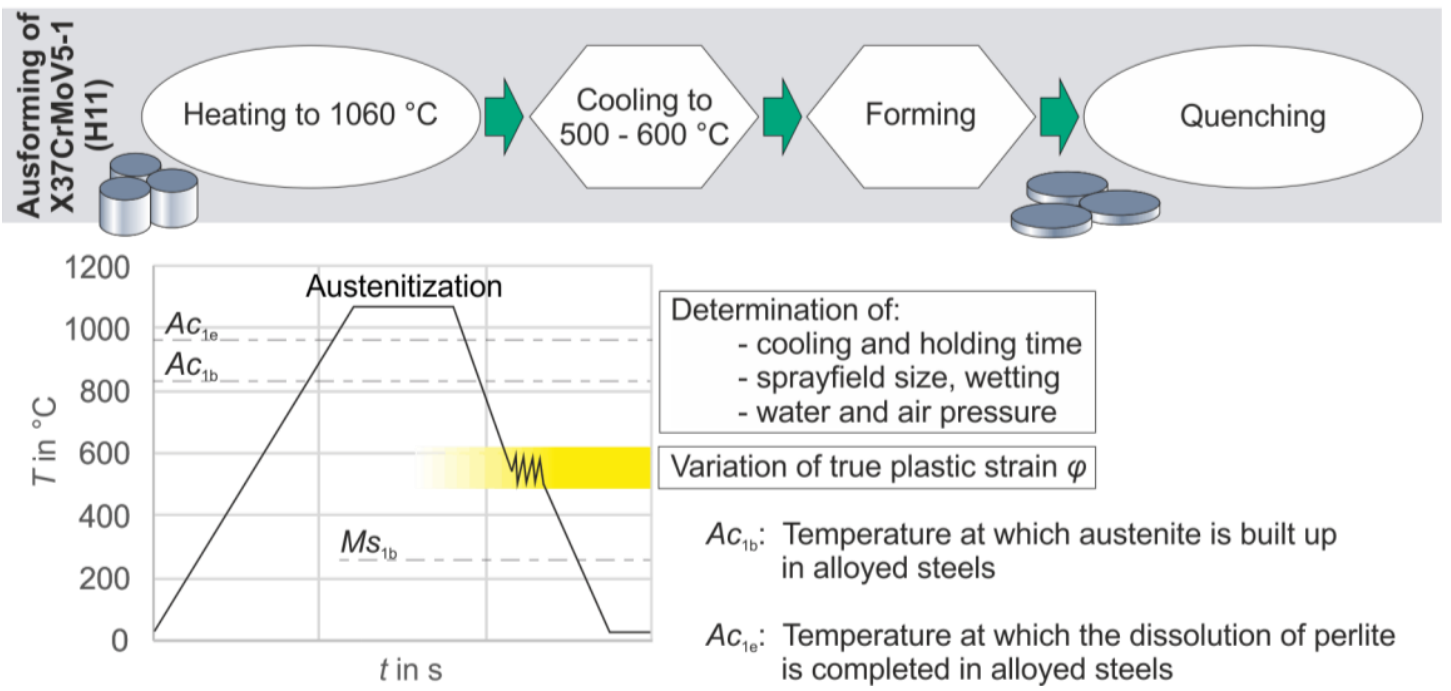

Figure 2 Depiction of the process sequence using the example of a simplified continuous TTT diagram

In order to adjust this temperature range while meeting the above-described requirements, preliminary tests were carried out with different spray heads and parameters using a thermal imaging camera (Figure 3 ). It was found that the spray head type 300-04508 (GERLIEVA), with an average cooling rate of $65.9 \mathrm{~K} / \mathrm{s}$, proved to be most suitable for the investigations providing sufficient accuracy without undercooling.

In the ausforming tests, the heated samples were placed on the upsetting plate within the press and were then cooled by a spray field directly before forming. The end of the first cooling step was determined by reaching the forming temperature. The cooling time $t_{\mathrm{c}}$ was varied between $1.3-2 \mathrm{~s}$ and the holding time $t_{\mathrm{h}}$ between $1-10 \mathrm{~s}$. The holding time was introduced after cooling to reduce the temperature gradient between the inside and the surface of the samples. After upsetting, the samples were quenched in water.
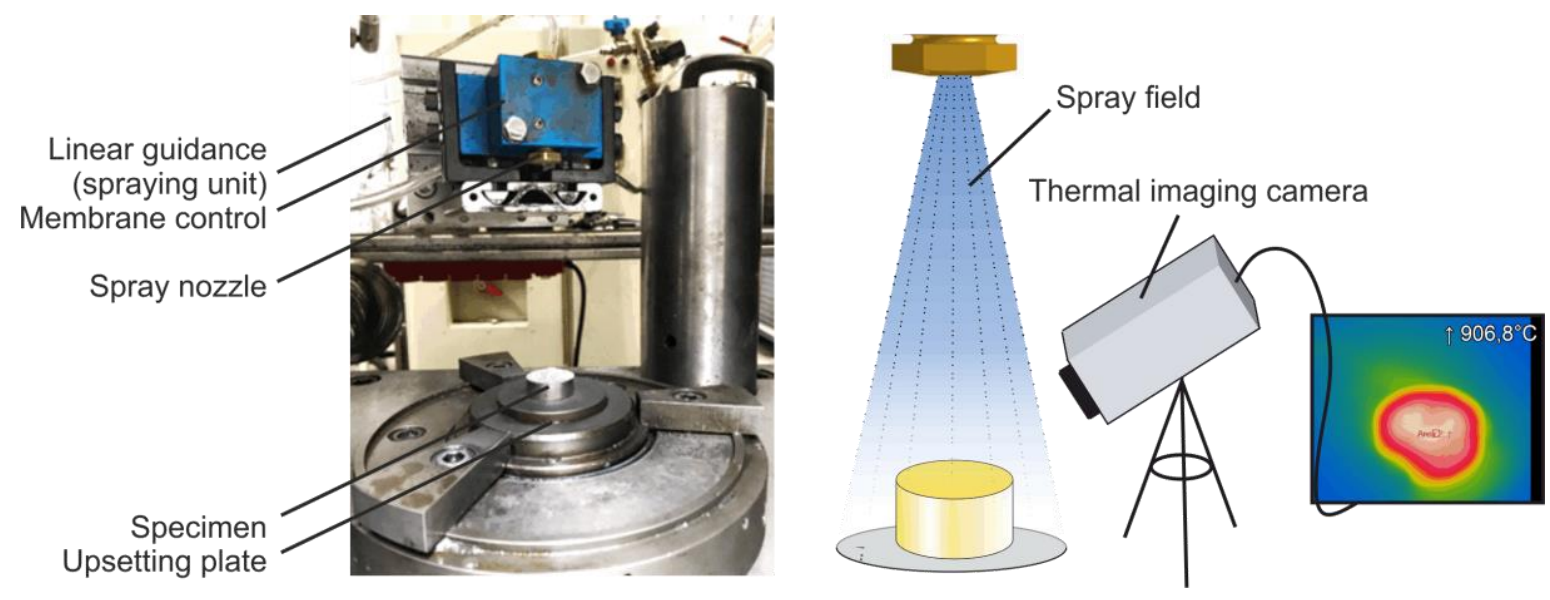

Figure 3 Tools, cooling device and thermal imaging record for the described analogy experiments

The forming tests were conducted on a Weingarten screw press type PSR 160. The upsetting tools were also made of X37CrMoV5-1 (H11) and were lubricated with Con Traer G 300 which was applied on the tools before positioning the hot specimen. After the tests, the surfaces of the samples were examined for material failure and hardness measurements were carried out. The lines of the hardness measurements on the halved specimens are shown in Figure 4. 


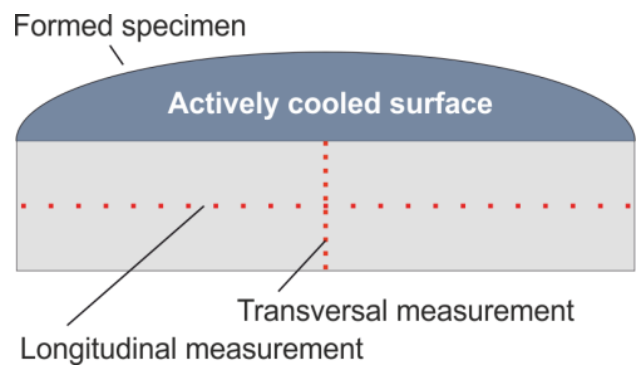

Figure 4 Measurement lines investigated in the hardness tests on a formed specimen

\section{RESULTS}

During quenching in a water bath to ambient temperature, crack formation occurred in many test series. The resulting material failures for the respective parameters are shown in Table 1. For the true plastic strain of 0.45 , no cracks occurred only with a spray time of $1.3 \mathrm{~s}$ and a holding time of $1 \mathrm{~s}$. At a true plastic strain of 0.25 , crack-free forming was shown up to a spraying time of $1.5 \mathrm{~s}$ and a holding time of $5 \mathrm{~s}$. Here, the forming stroke is significantly shorter than with $\varphi=0.45$ due to the lower material thickness of the specimens to be formed, which indicates lower stresses in the workpiece at the end of the forming process. Both the cooling and holding time show an influence on crack propagation during forming. Although tribological effects have not been investigated, they must be taken into account as they have a significant influence on the material flow, especially when it comes to surface enlargement and critical friction contact [5].

Table 1 Material failure in the test series

\begin{tabular}{|c|c|c|c|c|c|c|}
\hline Material failure & \multicolumn{3}{|c|}{$\varphi=0.25$} & \multicolumn{3}{c|}{$\varphi=0.45$} \\
\hline Cooling and holding time & $t_{\mathrm{c}}=1.3 \mathrm{~s}$ & $t_{\mathrm{c}}=1.5 \mathrm{~s}$ & $t_{\mathrm{c}}=2 \mathrm{~s}$ & $t_{\mathrm{c}}=1.3 \mathrm{~s}$ & $t_{\mathrm{c}}=1.5 \mathrm{~s}$ & $t_{\mathrm{c}}=2 \mathrm{~s}$ \\
\hline$t_{\mathrm{h}}=1 \mathrm{~s}$ & & & & & & \\
\hline$t_{\mathrm{h}}=5 \mathrm{~s}$ & & & & & & $t_{\mathrm{c}}$ : cooling time \\
\hline$t_{\mathrm{h}}=10 \mathrm{~s}$ & & & & & & \\
\hline
\end{tabular}

In some cases the material failure could already be detected by external observation, as shown in Figure $\mathbf{5}$. After a holding time of $10 \mathrm{~s}$ visible crack evolution occurred in the specimen with $t_{\mathrm{c}}=2 \mathrm{~s}$ and $t_{\mathrm{h}}=10 \mathrm{~s}$. For shorter holding times, the crack formation on the lower side of the specimen could only be detected under the microscope. Furthermore, a different bulging at the lower sample edges was detected, causally connected to the crack formation. During spray cooling, the tool surface is also wetted and the lubricant is partially removed, which has a negative effect on the tribological properties of the tool and workpiece contact during forming. In addition, the high axial temperature gradient can be seen as a negative influence on the process. This is indicated by the inhomogeneous bulging.

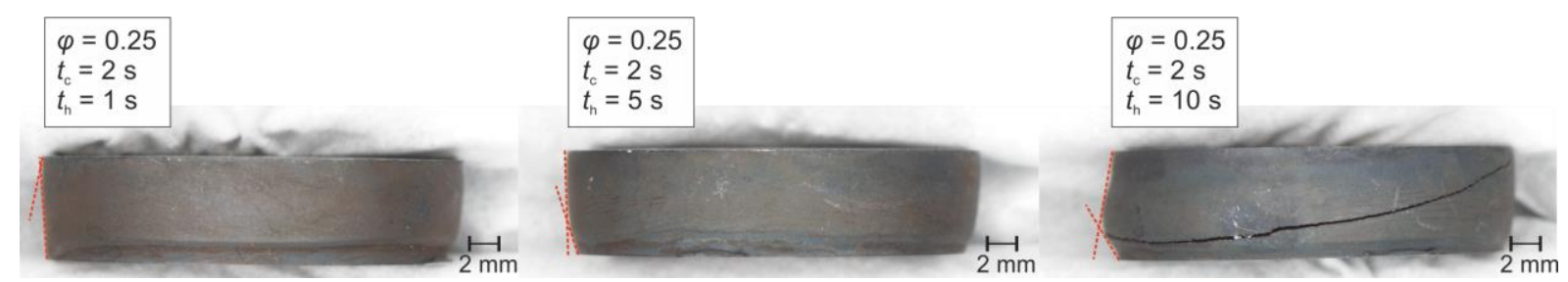

Figure 5 Specimen after forming with $\varphi=0.25, t_{c}=2 \mathrm{~s}$ and varied $t_{h}$

The interpolated hardness measurements in the transversal direction are shown in Figure 6. The specimen with higher true plastic strain are harder in the core area, where a longer holding time also shows effect. Here the ausforming effect is evident, since the highest true plastic strain occurs in the centre. The uppermost area 
close to the surface has a bainite structure, caused by atmosphere contact while heating and following decarburization. Due to the reduced carbon content, the bainite transformation is shifted towards shorter transformation times, which explains the appearance of the intermediate structure even after rapid cooling. The surfaces of the samples have the lowest hardness, as shown in the diagram.
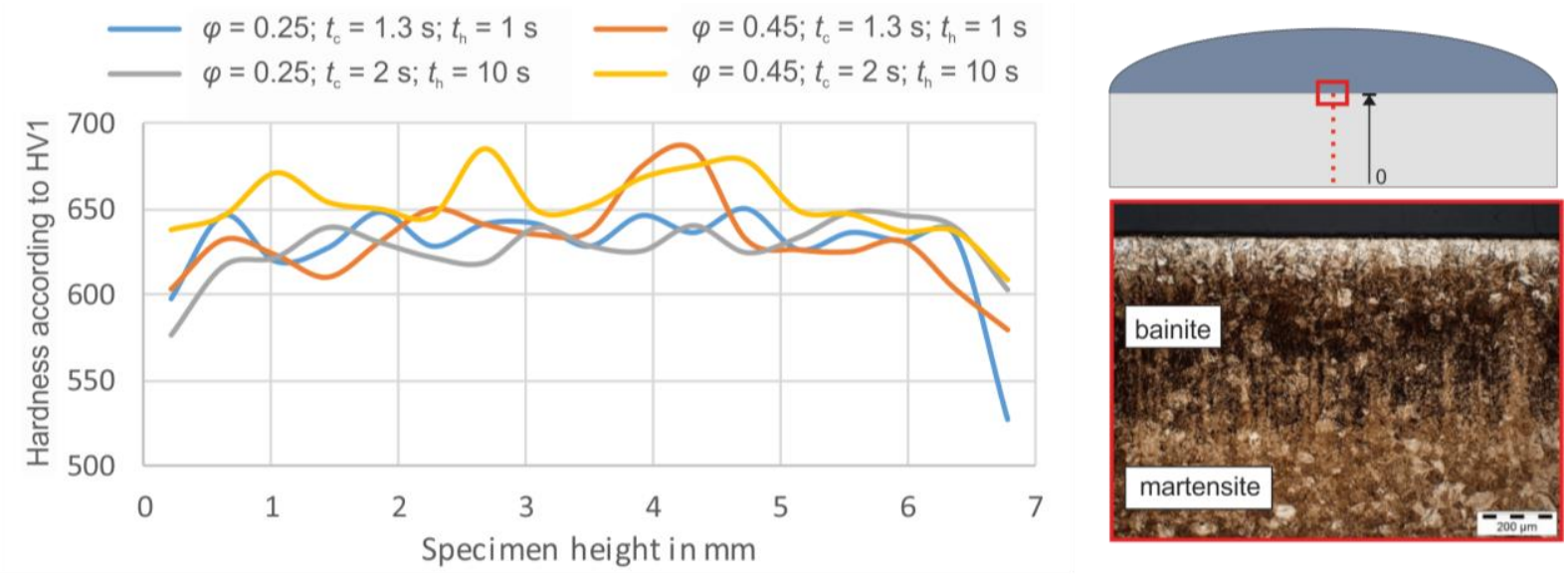

Figure 6 Interpolated hardness curves of transversal measurements and microstructure in surface area

The averaged and interpolated hardness values over the radius are shown for both invesigated true plastic strains in Figure 7. In longitudinal direction the hardness values differ significantly in terms of applied cooling and holding times. The global true plastic strain has a considerable influence on achieving an increased hardness value which indicates that the local temperature has fallen below recrystallization temperature and material displacements were transferred to martensite. Similar to the transversal measurement, the outermost values show a low hardness value due to the decarburised zone. Towards the centre, the hardness value approaches that of the transverse measurement. The martensitic microstructure in front of the bainitic structure shows the highest hardness values. A longer cooling and holding time is beneficial for achieving higher hardness in core direction, since the highest local true plastic strain occurred in this area. The highest hardness was achieved with $\varphi=0.45$, a cooling time of $2 \mathrm{~s}$ and a holding time of $10 \mathrm{~s}$. The plastic deformation could not be transferred to the material completely without material defects occurring. Nevertheless, it was shown that the extensive cooling in areas of higher deformation-induced material movement leads to a simultaneous reduction of the forming capacity and crack propagation.
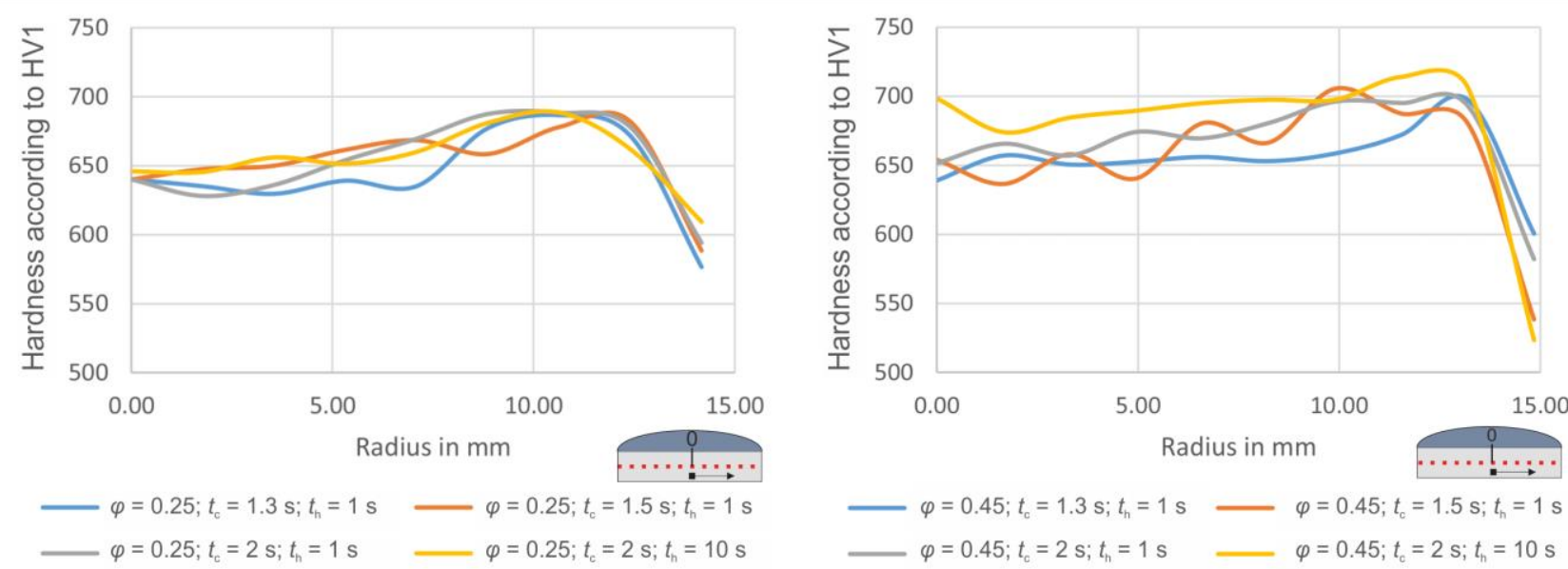

Figure 7 Hardness curves of longitudinal measurements averaged and interpolated on the radius for varied cooling and holding times ( $\varphi=0.25$ left; $\varphi=0.45$ right) 


\section{CONCLUSION}

With the process of ausforming, noticeably increased hardness values were achieved. The investigation has shown that the hardness increases with higher cooling times in the metastable austenite phase and thus lower forming temperature. Material failure occurred in specimens with long cooling and holding times. Here, it is challenging to generate a homogenous temperature. It could be shown that a longer holding time turns out to shift higher hardness values towards the centre. The deformation introduced into the material has an influence on the attainable hardness. At $\varphi=0.45$, higher hardness values are achieved than at $\varphi=0.25$. For the investigated true plastic strains, a cooling time of $1.5 \mathrm{~s}$ and a holding time of $10 \mathrm{~s}$ reached the highest hardness values but showed crack formation in both cases. At $\varphi=0.45$ merely short cooling and holding times were applicable without material failure. Due to the spray field between the upsetting tools, the lubricant layer which was applied before cooling was mostly ineffective, which is noticeable when the bulge is observed. The local true plastic strain depends on the friction and can lead to material failure in case of local overload. The metallic contact of the specimen with the tool represents a further influence that also contributes to high cooling rates on the lower side. The study also shows that the layer close to the edge cools early and thus does not deform. In order to avoid the formation of edge decarburization and bainite structures in the near-surface layer, the samples should be heated in a protective gas atmosphere. The results gained are to be transferred to the multi-stage forming of dies in the ongoing project. Here, mechanical load tests are to be carried out on sample geometries with ausformed die contours.

\section{ACKNOWLEDGEMENTS}

The results presented were obtained in the research project „Development and Investigation of Mechanical Properties of Hot Forging Dies by Bulk Forming and Thermomechanical Treatment” financed under project number 318628894 by the German Research Foundation (DFG). The authors would like to thank the DFG for financial support.

\section{REFERENCES}

[1] PASCHKE, H., YILKIRAN, T., LIPPOLD, L., BRUNOTTE, K., WEBER, M., BRAEUER, G., BEHRENS, B.-A. Adapted surface properties of hot forging tools using plasma technology for an effective wear reduction. Wear. 2015, vol. 330-331, pp. 429-438.

[2] BEHRENS, B.-A. Finite element analysis of die wear in hot forging processes. CIRP Annals. 2008, vol. 57, no. 1, pp. 305-308.

[3] HEINEMEYER, D. Untersuchungen zur Frage der Haltbarkeit von Schmiedegesenken. Dissertation. Hannover: Institut für Umformtechnik und Umformmaschinen, 1976.

[4] BERNS, H., THEISEN, W. Eisenwerkstoffe: Stahl und Gusseisen. Berlin, Heidelberg: Springer-Verlag, 2008.

[5] BEHRENS, B.-A., DOEGE, E., SPRINGUB, B. Transformation Induced Martensite Evolution in Metal Forming Processes of Stainless Steels. Steel research international. 2004, vol. 75, no. 7, pp. 475-482.

[6] DIRNFELD, S.F., KOREVAAR, B.M., SPIJKER, F. The transformation to austenite in a fine grained tool steel. Metallurgical Transactions. 1974, vol. 5, no. 6, pp. 1437-1444.

[7] KASPAR, R., PAWELSKI, O., KAPELLNER, W. Einfluß der Austenitumformung auf die Umwandlung von Stählen. In: LANGE, K., ed. Werkstoff und Umformung: Vorträge des 1.Workshop Stuttgart, 9. Juni 1986. Berlin, Heidelberg: Springer Berlin Heidelberg, 1986, pp. 68-95.

[8] DEUTSCHE EDELSTAHLWERKE [online]. [viewed 2019-09-22]. Available from: https://www.dewstahl.com/presse-medien/pressematerial/fachbeitraege/

[9] YANG, H., BHADESHIA, H. Austenite grain size and the martensite-start temperature. Scripta Materialia. 2009, vol. 60 , no. 7 , pp. 493-495. 